http://jmscr.igmpublication.org/home/

ISSN (e)-2347-176x ISSN (p) 2455-0450

crossref DOI: https://dx.doi.org/10.18535/jmscr/v8i1.144

\title{
Assessment of Clinical Profile, Laboratory Profile and Treatment Outcome of Tubercular Pleural Effusion treated under RNTCP daily fixed dose regimen
}

\section{Authors \\ Dr Varshith K, Dr R Muddarangappa, Dr Siddeshwaraswamy P, Dr Vinay K S, Dr Sharath Kumar S}

Sri Siddhartha Medical College Hospital \& Research Centre, Agalakote, Tumakuru, Karnataka-572107 *Corresponding Author

Dr Varshith K

Junior Resident, Department of General Medicine,

Sri Siddhartha Medical College Hospital \& Research Centre, Tumakuru, Karnataka, India

\begin{abstract}
Background: India accounts for $1 / 4^{\text {th }}$ of the global TB burden, EPTB takes many forms, and evidence regarding best practice for many aspects of case finding, diagnosis and treatment is lacking. The second most common form of EPTB, Pleural TB is a common cause of pleural effusion in India.

Aim: To assess the clinical profile, laboratory profile and treatment outcome of newly diagnosed patients with pleural TB treated under RNTCP.

Methods: All newly diagnosed patients of pleural tuberculosis from Nov $1^{\text {st }} 2017$ to Oct $31^{\text {st }} 2018$ aged $>18 y$ were included in the study. They were started on RNTCP daily fixed dose regimen after a detailed clinical examination and appropriate laboratory investigations. Patients were assessed during hospital stay, at discharge, monthly once during the course of treatment and after completion of treatment for symptoms, signs, complications due to disease and adverse drug-effect. Outcome was graded by treatment success, failure, death, loss to follow up, changed regimen.

Results: A total of 57 cases were studied, out of which $56 \%$ were males and $44 \%$ were females, commonest age of presentation was $18-39 y$ r (43.8\%). The most common symptom was fever (85.9\%), most common sign was stony dull note on percussion, $63.2 \%$ of the cases had BMI $18 \mathrm{~kg} / \mathrm{m}^{2}$, Pleural fluid cytology revealed elevated lymphocytes and proteins in 100\% of the patients. Treatment outcome recorded was treatment success in $77.2 \%$, loss to follow-up in $8.8 \%$, not evaluated in $7 \%$, death in $5.3 \%$ and regimen changed in $1 \%$ of the patients.

Conclusion: Pleural tuberculosis is more commonly affecting the reproductive age group and working individuals of the family and its treatment under RNTCP daily fixed dose regimen has a good clinical outcome.
\end{abstract}

Keywords: Tuberculosis, Pleural Effusion, RNTCP (Revised National Tuberculosis Control Programme).

\section{Introduction}

Tuberculosis is an infectious disease primarily involving the lung, but can also affect any organ in the body known as extra-pulmonary tuberculosis. Tuberculosis (TB) is an old diseasestudies of human skeleton have showed that it has 
affected humans for thousands of years ${ }^{1}$. Around $5-10 \%$ of estimated 1.7billion people infected with M. tuberculosis will develop TB disease in their lifetime, most commonly affecting the people infected with HIV and risk factors such as diabetes, undernourishment, smokers and alcohol consumption. India accounts for one fourth of global TB burden and has remained a disease of public health importance which is known to inflict large quantum of socioeconomic cost on the society ${ }^{3}$.

Although Pulmonary TB is the most common presentation of TB disease, Extra pulmonary tuberculosis (EPTB) is also an important clinical problem, commonly missed because of diagnostics difficulties ${ }^{4,5}$. Diagnosis and treatment of various types of EPTB is difficult due to lack of adequate infrastructure and resources used in the peripheral level of health facilities to identify, diagnose and treat EPTB, absence of skilled and trained staff for appropriate sample collection, transportation and diagnosis \& also due to uncertainty among clinicians about the optimum duration of treatment and treatment end-points and as most of the cases are being treated outside the public sector there is lack of data on EPTB.

The term EPTB is defined as the isolated occurrence of TB in any part of the body other than lungs. The most common sites of extrapulmonary tuberculosis are lymph nodes, pleura, genitourinary tract, bones and joints, meninges, peritoneum, pericardium and other abdominal organs $7,8,9,10,11$. Pleural effusion due to tuberculosis is the second most common form of extrapulmonary tuberculosis (EPTB). Even in developed nations, TB pleural effusion is increasingly recognized ${ }^{5}$, asthe incidence of TB pleural effusion in human immunodeficiency virus I acquired immuno-deficiency syndrome (HIV/AIDS) has been variously reported to range from 15 to $90 \%$ with effusion being more common in patients with higher CD4+ counts ${ }^{6-8}$. The recent emergence of HIV pandemic, wide spread use of immune suppressive drugs, immuno-compromised states other than HIV like
Diabetes, extremes of age, disease and disability has increased the risk of developing $\mathrm{TB}^{12,13}$. This study was conducted to assess the clinical profile and the treatment outcome of tubercular pleural effusion treated under new RNTCP guidelines as shown in Table $\mathbf{1}$ and fixed drug dose regimen based on weight bands is shown in Table 2 .

\section{Materials and Methods}

A prospective study, all newly diagnosed tubercular pleural effusion patients of any sex and age $>18$ years over a period of 1year (1st Nov'1731 st Oct'18) admitted at sri siddhartha medical college hospital and research centre, after informed written consent a detailed history regarding the illness were recorded. A thorough physical examination of all systems was carried out, appropriate laboratory and radiological investigation details were recorded. Patients diagnosed with both pulmonary and extrapulmonary tuberculosis and those patients requiring regimen other than category-1 antitubercular therapy under RNTCP guidelines were excluded.All patients were assigned categories as per RNTCP criteria, patients was closely assessed during hospital stay, at discharge, monthly once during the course of treatment and after completion of treatment for signs, symptoms, complications due to disease process and adverse drug effects. Outcome at follow up were graded as Treatment success, Treatment failure, Death, Loss to follow up, Not Evaluated, Treatment Regimen Changed. The data obtained from the patients with regard to clinical profile, laboratory investigations and treatment outcome would be presented in tabulated forms. Data entry will be done using excel spread sheet and descriptive statistics including frequencies of various functional outcomes will be calculated using Epi.info

\section{Results}

Age distribution of pleural effusion cases in this study showed maximum number of cases belonging to 30-39 years of age indicating that 
working individuals of the family are affected the most. Shown in Table 3.

Sex distribution in this study showed male predominance i.e $56 \%$ of cases and females $44 \%$ cases and male to female ratio is $1.3: 1$. as shown in Graph 1

Table 4 shows occupation distribution, here maximum number patients are farmers by occupation with $45.6 \%$ cases. Followed by homemakers $26.3 \%$.

Symptom distribution in pleural tuberculosis in the present study is with most common presentation being fever in $85.6 \%$, followed by cough in $78.9 \%$ and loss of appetite in $73.7 \%$ cases.shown in Graph 2

The most common sign seen in general physical examination is Pallor in $65 \%$ cases. Position of Trachea in relation to effusion was observed to be on opposite side in $65 \%$ cases, same side in $26 \%$ cases and central in $9 \%$ of cases. Dullness on Percussion was elicited in $100 \%$ of cases and also absent / decreased breath sounds in $100 \%$ of cases.

Table 5 shows BMI at admission before the beginning of the treatment with maximum number of cases having BMI less than $18.5 \mathrm{~kg} / \mathrm{m}^{2}(63.2 \%$ cases).

Routine laboratory investigations showed 44\% patients were anaemic, and FBS more than $126 \mathrm{mg} / \mathrm{dl}$ in $19.3 \%$ patients, with $4(7.01 \%) \mathrm{HIV}$ positive cases, one each chronic liver disease and chronic kidney disease patients.

Amount of pleural effusion in patients studied with mild effusion in 9 cases moderate effusion in 44 cases and large effusion in 4 cases based on radiological findings.

Table 6, 7, 8 and 9 shows Pleural fluid analysis of 57 patients, with cell count ranging from 30006000 in $54.4 \%$ patients with more than $90 \%$ lymphocyte predominance in $54.4 \%$ cases. $78.9 \%$ patients had protein ranging from $4-6 \mathrm{~g} / \mathrm{dl}$.with pleural fluid sugars $<60 \mathrm{mg} / \mathrm{dl}$ in $86 \%$ of cases.

Among 57 cases studied adenosine deaminase (ADA) values were recorded only in 48 cases due to financial constraints in the left out 9 cases. Out of these 48 cases 5 cases had ADA less than 50 IU/L, 15 cases had ADA between 50-100 IU/L, 20 cases had ADA between 100-150 IU/1 and 8 cases had ADA above 150 IU/L.

Table 10 shows treatment outcome in TB pleural effusion. Here 44 out of 57 cases accounting to $77.2 \%$ completed treatment which is taken has treatment success in EPTB cases, 5 patients could not be traced resulted in loss to follow up, 4 patients were not evaluated due to transfer out, 1 patient treatment regimen was changed following adverse drug reaction, 3 patients died during the course of the treatment.

Table 1: RNTCP guidelines

\begin{tabular}{|l|l|}
\hline New Guidelines & Previous Guidelines \\
\hline Daily regimen & Intermittent regimen \\
\hline $\begin{array}{l}\text { Ethambutol in } \\
\begin{array}{l}\text { Continuatino Phase of } \\
\text { both categories I and II } \\
\text { regimen }\end{array}\end{array}$ & $\begin{array}{l}\text { Ethambutol in Continuation } \\
\text { Phase of category II regimen } \\
\text { only }\end{array}$ \\
\hline $\begin{array}{l}\text { Fixed dose combination } \\
\text { as per weight bands }\end{array}$ & $\begin{array}{l}\text { No fixed dose , limited } \\
\text { weight bands }\end{array}$ \\
\hline $\begin{array}{l}\text { No need of extension of } \\
\text { Intensive phase }\end{array}$ & $\begin{array}{l}\text { Extension of intensive phase } \\
\text { for 1month if sputum is } \\
\text { positive at the end of IP }\end{array}$ \\
\hline $\begin{array}{l}\text { Follow-up clinical, } \\
\text { laboratory investigation }\end{array}$ & Follow-up laboratory only \\
\hline
\end{tabular}

Table 2: Fixed drug dose regimen based on weight bands

\begin{tabular}{|lc|c|c|}
\hline $\begin{array}{l}\text { Weight } \\
\text { Category } \\
\text { in kg }\end{array}$ & $\begin{array}{c}\text { Intensive Phase } \\
\text { HRZE } \\
75 / 150 / 400 / 275\end{array}$ & $\begin{array}{c}\text { Continuation Phase } \\
\text { HRE } \\
75 / 150 / 275\end{array}$ & $\begin{array}{c}\text { Inj. } \\
\text { Sterptomycin }\end{array}$ \\
\hline $25-39$ & 2 & 2 & 0.5 \\
\hline $40-54$ & 3 & 3 & 0.75 \\
\hline $55-69$ & 4 & 4 & 1 \\
\hline$>/=70$ & 5 & 5 & 1 \\
\hline
\end{tabular}

Table 3: Age Distribution

\begin{tabular}{|l|c|}
\hline Age & Cases \\
\hline$>80$ & 2 \\
\hline $70-79$ & 4 \\
\hline $60-69$ & 6 \\
\hline $50-59$ & 9 \\
\hline $40-49$ & 11 \\
\hline $30-39$ & 14 \\
\hline $18-29$ & 11 \\
\hline
\end{tabular}




\section{JMSCR Vol||08||Issue||01||Page 885-891||January}

Table 4: Occupation Distribution

\begin{tabular}{|l|c|}
\hline Occupation distribution & No. Of cases \\
\hline Farmer & 26 \\
\hline Housewife & 15 \\
\hline Daily Labour & 8 \\
\hline Students & 4 \\
\hline Others & 4 \\
\hline
\end{tabular}

Table 5: BMI Distribution

\begin{tabular}{|l|c|}
\hline BMI in $\mathrm{Kg} / \mathrm{m}^{2}$ & No. Of cases \\
\hline$<18.5$ & 36 \\
\hline $18.5-24.9$ & 18 \\
\hline$>25$ & 3 \\
\hline
\end{tabular}

Table 6: Pleural fluid Cytology part 1

\begin{tabular}{|l|c|}
\hline Cell count in per $\mathrm{mm}^{3}$ & No. Of cases \\
\hline$<1000$ & 5 \\
\hline $1000-3000$ & 18 \\
\hline $3000-6000$ & 31 \\
\hline$>6000$ & 3 \\
\hline
\end{tabular}

Table 7: Pleural fluid Cytology part 2

\begin{tabular}{|l|c|}
\hline Lymphocytes percentage & No. Of cases \\
\hline $60-70$ & 1 \\
\hline $70-80$ & 4 \\
\hline $80-90$ & 21 \\
\hline$>90$ & 31 \\
\hline
\end{tabular}

Table 8: Pleural fluid bio-chemical analysis part 1

\begin{tabular}{|l|c|}
\hline Pleural fluid Proteins in $\mathrm{g} / \mathrm{dl}$ & No. Of cases \\
\hline $2-4$ & 10 \\
\hline $4-6$ & 45 \\
\hline$>6$ & 2 \\
\hline
\end{tabular}

Table 9: Pleural fluid bio-chemical analysis part 2

\begin{tabular}{|l|c|}
\hline Pleural fluid Sugars in $\mathrm{mg} / \mathrm{dl}$ & No. Of cases \\
\hline$<60$ & 49 \\
\hline$>60$ & 8 \\
\hline
\end{tabular}

Table 10: Treatment Outcome of Pleural TB

\begin{tabular}{|l|c|c|}
\hline Treatment Outcome & No. Of cases & Percentage \\
\hline Treatment success & 44 & $77.2 \%$ \\
\hline Loss to follow-up & 5 & $8.8 \%$ \\
\hline Not evaluated & 4 & $7.0 \%$ \\
\hline Regimen changed & 1 & $1.2 \%$ \\
\hline Death & 3 & $5.3 \%$ \\
\hline Treatment failure & 0 & 0 \\
\hline
\end{tabular}

\section{Sex Distribution}

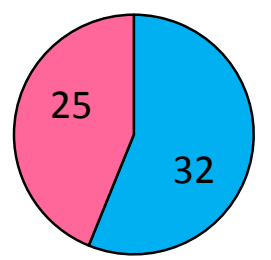

Male

$\square$ Female

\section{Graph 1: Sex Distribution}

\section{Symptom Distibution of Plural TB}

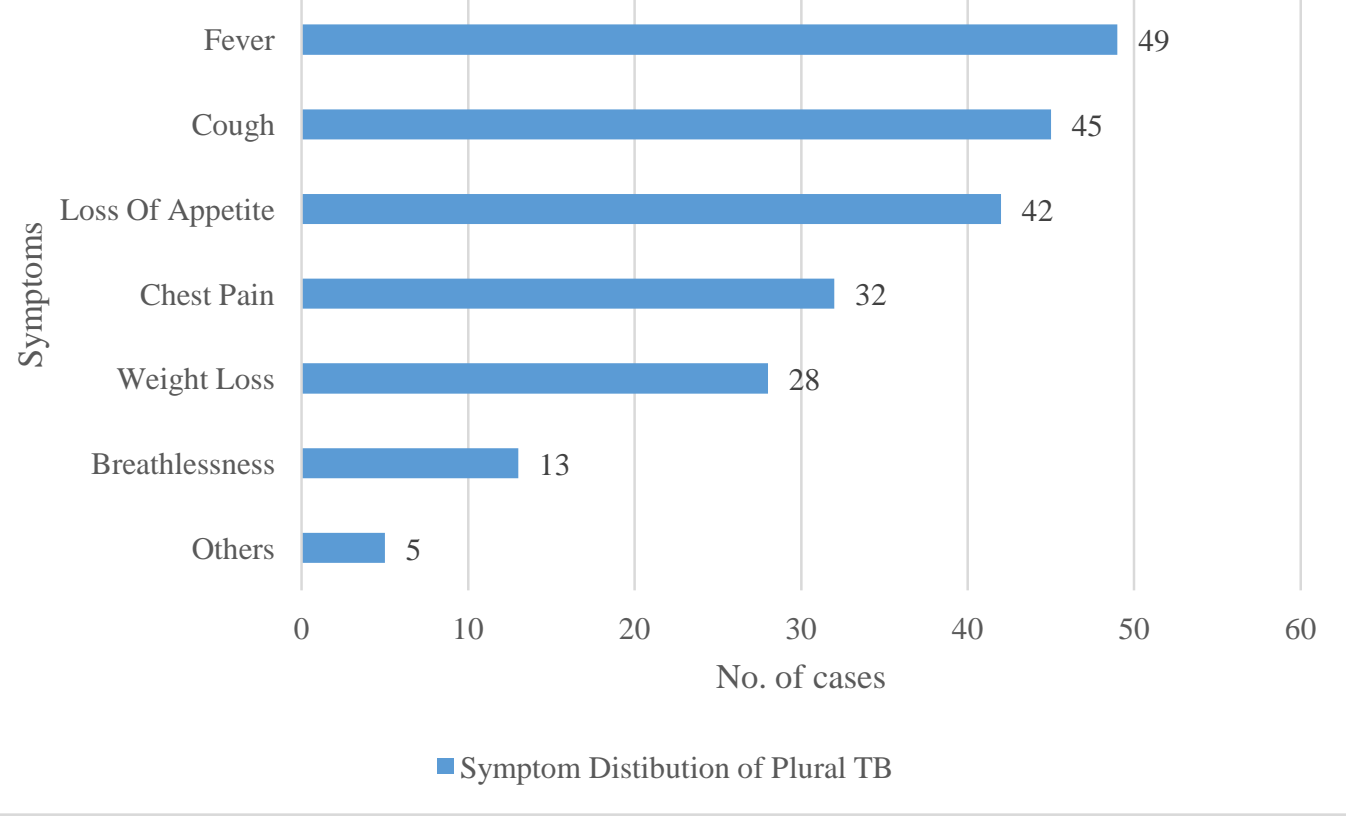

Graph 2: Symptom Distribution 


\section{Discussion}

Tuberculous pleural effusion is the commonest cause of a unilateral pleural effusion in countries with a high TB burden. It is also the commonest form of HIV-related extra-pulmonary disease, with a mortality of about $20 \%$ in the first 2 months on treatment. Management of tuberculous pleural effusion should aim at starting TB treatment promptly and determining the HIVstatus of the patient.

\section{Clinical features}

$>$ Presentation is most often acute with a non-productive cough, chest pain, shortness of breath and high temperature.

$>$ The chronic form is found predominantly in the elderly and presents with systemic symptoms such as weakness, anorexia, weight loss, slight fever, cough, and chest pain.

$>$ Findings on clinical examination may include: - Tracheal and mediastinal shift away from the side of the effusion Decreased chest movement - Stony dullness on percussion on the side of the effusion.

\section{Diagnosis}

$>$ Suspected pleural effusions should be confirmed immediately by chest x-ray. This will show unilateral, uniform white opacity, often with a concave upper border $^{14}$.

$>$ Pleural aspiration should be undertaken wherever possible: the fluid is a straw coloured exudate and has protein content $>30 \mathrm{~g} / \mathrm{l}$. The white cell count is high (10002500 per $\mathrm{mm} 3$ ) with predominantly lymphocytes. The adenosine deaminase (ADA), which is a measure of the lymphocyte count, is raised $>30 \mathrm{IU}^{15}$.

Failure of the aspirate to clot does not exclude $\mathrm{TB}$ as it may indicate lower protein content in wasted patients; the predominance of lymphocytes (>50\%) confirms a TB diagnosis.
$>$ Since the number of bacilli present is relatively small, AFB are not usually seen on microscopy of centrifuged specimens of pleural fluid, however, culture may be positive.

$>$ If aspiration is not possible, commence TB treatment unless the chest $\mathrm{x}$-ray suggests a different diagnosis.

$>$ Differential diagnosis of a pleural exudate includes malignancy, a post-pneumonia effusion and pulmonary embolism ${ }^{16}$.

$>$ Bilateral effusions or those with cloudy or bloody aspirates should be investigated further.

$>$ Xpert MTBRIF may be requested on pleural biopsies to confirm.

The treatment outcome of tuberculosis is classified as ${ }^{15}$ :

- Cure: cure was defined as completion of treatment and $>5$ consecutive negative culture results in the final 12 months of treatment.

- Treatment Completion: referred to completion of therapy but without bacteriological documentation of cure.

- Treatment success has been defined as the percentage of patients in whom the treatment was either cured or completed.

- Treatment Failure: was defined as having more than one positive culture in the final 12 months of therapy, or if any one of the final three cultures was positive, or if more than one drug in the treatment regimen was replaced. Or if the treatment was terminated due to adverse events or no clinical improvement.

- Default was defined as an interruption in treatment for $>2$ consecutive months for any reason.

- Death was defined as all causes of mortality during the course of the TB treatment.

- Loss to follow up: A TB patient whose treatment was interrupted for 2 consecutive months or more. 
- Not Evaluated: ATB patient whom no treatment outcome is assigned, this includes cases transferred out to another treatment unit as well as cases whom the treatment outcome is unknown to the reporting unit.

- Treatment Regimen Changed: this involves patients whose treatment was changed due to adverse drug events from the initial first line management drugs.

Six months intermittent regimens are considered standard and effective therapy in most parts of the world and form the foundation of a current recommendation of Revised national tuberculosis control programme ${ }^{17}$. From Nov 2017 onwards RNTCP started a daily fixed drug dose regimen based on the weight bands as shown in Table 2 and also introduced the drug Ethambutol in the continuation phase of anti tubercular therapy. This study was done based on the RNTCP daily fixed dose regimen and the use of Ethambutol in continuation phase.

In the present study a total of 57 cases were studied, out of which $56 \%$ were males and $44 \%$ were females, commonest age of presentation was $18-39 y$ r (43.8\%). The most common symptom was fever $(85.9 \%)$, most common sign was stony dull note on percussion, $63.2 \%$ of the cases had $\mathrm{BMI}<18 \mathrm{~kg} / \mathrm{m}^{2}$, Pleural fluid cytology revealed elevated lymphocytes and proteins in $100 \%$ of the patients. Treatment outcome recorded was treatment success in $77.2 \%$, loss to follow up in $8.8 \%$, not evaluated in $7 \%$, death in $5.3 \%$ and regimen changed in $1 \%$ of the patients.

\section{Conclusion}

Pleural effusion is commonly encountered in our day to day practice in India, TB being the most common etiology, establishing the cause and its early treatment based on RNTCP guidelines reduces the morbidity and mortality.

An effort should be made in identifying the risk patients and effectively treating the comorbidities, thereby reducing the TB burden of India.
Higher reporting in Tertiary centers like Medical college hospitals, necessitates the need for ongoing medical education for doctors and DOTS providers.

RNTCP is the main functioning unit in prevention and cure of TB in India.

\section{Limitation of the study}

This study fails to highlight the adverse drug events in response to anti-tubercular therapy under RNTCP guidelines.

\section{Acknowledgement: NIL}

\section{Financial Support: Nil}

\section{References}

1. Hershkovitz I, Donoghue HD, Minnikin DE, May H, Lee OY, Feldman M, et al. Tuberculosis origin:the Neolithic scenario. Tuberculosis (Edinb).2015;95 Suppl 1:S122-6.

(https://www.ncbi.nlm.nih.gov/pubmed/25 726364, accessed 3 July 2018).

2. Sakula A. Robert Koch: centenary of the discovery of the tubercle bacillus, 1882 . Thorax. 1982;37(4):246-51. (https://www.ncbi.nlm.nih.gov/pubmed/61 80494).

3. Global Tuberculosis report 2017- world health organization.

4. Deribew A, Negussu N, Melaku Z, Deribe $\mathrm{K}$ : investigation outcomes of tuberculosis suspects in the health centres of Addis Ababa, Ethiopia. Eth Med J 2011;6(4): e18614.

5. Grange Jm \& Zumla, editor. MAnsons tropical disease. $21^{\text {st }}$ edition. London; Sauders, 2003; 995-1052.

6. Golden MP, Vikram HR. Extrapulmonary tuberculosis: an overview. Am Fam Physician. 2005; 72(9):1761-8.

7. Sharma SK, Mohan A (2004). Extrapulmonary tuberculosis. Ind J Med Res. 120(4):316-53. 
8. Chalke. some historical aspects of tuberculosis. public health. 1959; 74(3): 83-95.

9. TB- india history 2018. http://www.tbfacts.org/tb-india-history/.

10. Technical And Operational Guidelines For Tuberculosis Conrol; Central TB Divison, Directorate General Of Health Services, Ministry Of Health and Family Welfare, New Delhi:0ct 2016.

11. Ade S, Harries AD, Trebucq A, Ade G, Agodokpessi G, et al. (2014) National Profile and Treatment Outcomes of Patients with Extrapulmonary Tuberculosis in Benin. PLoS ONE 9(4): e95603.

12. Anju Jain Indian J Clin Biochem. 2011 July; 26(3): 269-273.

13. Sharma SK, Mohan A. Extra pulmonary Tuberculosis. Review article. Indian J Med Res 2004; 120:316-53.

14. Golden MP, Vikram HR: Extra pulmonary tuberculosis: an overview.^/?? Fam Physician 2005, 72(9): 1761-1768.

15. Chalke. some historical aspects of tuberculosis, public health. December 1959; 74(3): 83-95.

16. TB- india history 2014. Available from: http://www.tbfacts.org/tb-india-history/. accessed on December, 2015.

17. WHO estimated burden of tuberculosis in India, 2016. Available from :http://www.tbfacts.org/tb-statistics/, accessed on December 1, 2019. 